\title{
Factors Influencing Employees' Intention to Use Cloud Computing
}

\author{
Ali Tarhini ${ }^{1}$, Ra'ed Masa'deh ${ }^{2}$, Ali Al-Badi ${ }^{1}$, Majdolen Almajali ${ }^{3} \&$ Sufian Hussien Alrabayaah ${ }^{3}$ \\ ${ }^{1}$ College of Economics and Political Science, Department of Information Systems, Sultan Qaboos University, \\ Muscat, Sultanate of Oman \\ ${ }^{2}$ Department of Management Information Systems, The University of Jordan, Amman, Jordan \\ ${ }^{3}$ Department of Food and Beverage Management, The University of Jordan, Amman, Jordan
}

Correspondence: Ali Tarhini, College of Economics and Political Science, Department of Information Systems, Sultan Qaboos University, Muscat, Sultanate of Oman. Tel: 974-5012-1922.

Received: May 4, 2017

doi:10.5430/jms.v8n2p47
Accepted: May 20, $2017 \quad$ Online Published: May 23, 2017

URL: https://doi.org/10.5430/jms.v8n2p47

\begin{abstract}
This paper aims to investigate the effects of perceived ease of use, perceived usefulness, self-efficacy, trust, job opportunity, top management support, competitive pressure, and regulatory support on employees' behavioral intention to use cloud computing. Data was collected by means of self-administrated questionnaire containing 25 items from 205 employees' working in three, four, and five star hotels. Multiple regression analysis was conducted to test the research hypotheses. Results of the current study revealed that there are significant impacts of four independent variables (i.e. job opportunity, top management support, competitive pressure, and regulatory support) on behavioral intention (BI) to use cloud computing; whereas four independent variables (i.e. perceived ease of use, perceived usefulness, self-efficacy, and trust) have no significant impact on BI. The results of T-test also showed that there is a significant difference in the impact of BI to use cloud computing in favor of gender. On the other hand, the results of ANOVA's test showed that there is no significant difference in the impact of BI that can be attributed to age, educational level, and personal income; whereas a significant difference found in favor of work position and hotel's classification. In light of these findings, implications to both theory and practice are discussed.
\end{abstract}

Keywords: cloud computing, behavioral intention, technology adoption, hotels, Arab world

\section{Introduction}

The word "cloud" in cloud computing tells very little and it may be even misinforming (Al-lawati \& Al-Badi, 2016). "I hated it, but I finally gave up", says Carl Bass, President and CEO of Autodesk. He added, "I didn't think the term helped explain anything to people who didn't already know what it is". With the development of computer science and the emersion of the internet, cloud computing has improved from being an abstractor sketches into concrete business paradigm (Al-Badi et al., 2017). Cloud computing enables customers to rent IT infrastructure, platform, and software services in the cloud when needed. Thus, cloud clients can deploy their business applications, store data, and run analyses via the internet on a pay-per-use basis (Al-Musawi et al., 2015). Cloud computing revolutionizes the traditional IT adoption with the special and unique characteristics listed above. In the past, expensive IT innovations were usually adopted first by large firms since they could only afford them. Nowadays, it is widely believed that cloud computing will serve small and medium-sized enterprises (SMEs) (Hsu, et al., 2014).

One of the most popular technologies in web 2.0, Cloud Computing (CC) systems provide on - demand network based access to subscribers for the metered usage of an easily accessible and secure collection of remotely available information technology (IT) which enabled resources and capabilities inducing network, servers, storage, applications and services (Sharma, et al., 2016). The coinage of the term cloud computing could be traced to two individuals, who worked for Compaq computer: Geoge Favaloro, a Compaq marketing executive, and Sean O'Sullivan the founder of defunct business Net centric, but the creation of this term did not become widely known till another decade. In its modern context occurred on August 9, 2006 when Google CEO Eric Schmidt introduced the term at an industry conference "what's interesting [now] is that there is an emergent new model," Schmidt said "I don't think people have really understood how big this opportunity really is. It starts with the premise that the data service and architecture should be on servers we call it cloud computing - they should be in a cloud somewhere" (Daylami, 2015). 
The National Institute of Standard and Technology (NIST P 800-145) defines cloud computing as follows: "cloud computing is a model for enabling convenient on - demand network access to a shared pool of configurable computing resources (e.g. network, servers, storage, applications, and services". It can be rapidly provisioned and released with minimal management effort or service provider interaction (Daylami, 2015). Companies start to realize the advantages of cloud computing and how it can offer benefits and enhancements for their business, reduce hardware cost, improve performance of computers and service, reduce maintenance issues and, low software cost and unlimited storage capacity. However, some organizations have difficulties in using this new technology (Sharma et al., 2016). The few drawbacks are the requirements of constant high-speed internet access (since most applications do not work well with low - speed connection) and stored data might not be secure (AlKharusi \& Al-Badi, 2016; Sharma et al., 2016).

Small businesses need to consider the advantages, drawbacks and the effects of cloud computing on their organizations and usage practices before approving its adoption and use. The need for cloud computing to deliver real value is a major issue for small businesses. For this reason, issue a round migrating application system to the cloud and satisfying the need of small businesses should be investigated. The cost factor is important but customer relation, public image, flexibility, business are equally important as well, since large organizing are complex, there is a need to understand the major concept of cloud computing, including space time, cost, availability, privacy and security (Alijani, et al., 2014).

There is a huge cost saving for small firms due to the subscription model. A 70\% reduction has been observed since adopting AWS (Amazon Web service) as the cloud vendor (CC2011) AWS has also reduced their prices a couple of time in three years despite the absence of competitive forces. European SMES which are more risk averse, compared to USA SMES, appreciate this reduction affixed IT assets cost as well as the reduction of maintenance of IT assets, resulting in reducing the entry barriers (Gupta, et al., 2013).

Small business employees who are often work outside the actual office location and hence having easy access to their data (using the mobile devices) are a big plus, and this needs the employees to have access from remote locations as well as the increasing number of online transactions required a cloud computing solution. Accounting and finance work has been outsourced to the cloud leaving more time for small businesses executives to spend on strategic work and initiatives. The cloud approach helps to eliminate administrative overhead and allows access from any geographical location, from any device and from any organization. Less powerful device (smartphone, notebooks) are able to make most of the company's backend IT system via simple web - based interface like AWS management console (Gupta, et al., 2013).

This study aims to examine the effects of perceived ease of use, perceived usefulness, self-efficacy, trust, job opportunity, top management support, competitive pressure, and regulatory support on employees' behavioral intention to use cloud computing services in hotels.

\section{Literature Review}

\subsection{Perceived Ease of Use and Behavioral Intention to Use Cloud Computing}

Similar to perceived usefulness, perceived ease of use (PEOU) is an integral component of Technology Acceptance Model (TAM). PEOU may differ depending on the varying degrees of expertise in interacting with and utilizing cloud computing services. Whereas users may be become familiar with various internet services and find them easy to use in a shorter time period, the same need not be true in the case of cloud computing services. Several studies in the information systems adoption literature including new technologies discuss the influence of PEOU on their acceptance; for example, internet banking and e-learning technologies (Tarhini et al., 2015a; Al-Qirim et al., 2017), all the aforementioned studies show that ease of use plays an important role in the acceptance of a relatively new information technology. On the contrary, literature also contains studies that have not found PEOU to be a significant factor (Sharma et al., 2016). Hence, we provide the following hypothesis:

\subsection{Perceived Usefulness and Behavioral Intention to Use Cloud Computing}

The perceived usefulness (PU) can be a function of the learning value in terms of upgradation of technological knowledge (Tarhini et al., 2015b; El-Masri \& Tarhini, 2017). In case of smartphones adoption, perceived usefulness is viewed as the increased convenience and ability to accomplish daily tasks and was found to be an important determinant of smartphone adoption (Sharma et al., 2017). Conducting a study on mobile cloud services and their investigation seeks to explain the relationship between adoption and job performance improvement (Masa'deh, 2016). PU was found to influence the job performance of the users (Maqableh et al., 2014). Cloud computing is known to be useful in several ways; the user is not restricted by location, offers several opportunities to learn new 
softwares and access a range of hardware and software resources that are not owned internally by the company (Al-Qirim, 2011). All these advantages enable the user effectively to learn and improve job performance (Masa'deh et al., 2017). Therefore, it would be worthwhile to explore if these benefits influence the perceived usefulness and subsequently the cloud computing adoption decision (Sharma et al., 2016).

\subsection{Self-efficacy and Behavioral Intention to Use Cloud Computing}

Self-efficacy known as "the extent or strength of one's belief in one's own ability to complete a task". Computer self-efficacy has been observed as an important factor influencing the users' decision to adopt computer related technology. Self-efficacy seeks to measure the confidence that an individual possesses in performing the requisite tasks using the technology, computer systems and refers to the level of confidence exhibited by IT professionals in their ability to use computer systems. Self-efficacy has an important role in increasing the customer's knowledge and skills associated with a service process and proposed as a key organization strategy to keep and manage customer's satisfaction. Researches had pointed out that there is a need to elevate e-service encounter by incorporating enhanced user learning through the use of e-services rather than focusing only on the superior website design and unambiguous navigation instructions. An individual who has a higher degree of computer self-efficacy is expected to feel more comfortable in learning new information, which are related to the internet usage activities. Cloud computing services are relatively new phenomena in the domain of internet related activities, which involved various computing devices. Based on the support from the information systems literature, it can be observed that the higher computer self-efficacy leads to achieve desired results (Sharma et al., 2016; Dwivedi \& Mustafee, 2010; Masa'deh et al., 2016).

\subsection{Trust and Behavioral Intention to Use Cloud Computing}

Trust is an important factor affecting adoption of technology (Yadav et al., 2016; Tarhini et al., 2016; Abbasi et al., 2015). As cloud computing services are relatively new concept among internet service integrity aspects of this technology needs to be explored. It is important for cloud computing industry to ensure adequate privacy and security for sensitive information of users while using the services of cloud computing (Sharma et al., 2016). The security issues in cloud computing leads to a number of privacy concerns (Karajeh et al., 2016). Privacy is complex issue that has different interpretations depending on contexts, cultures and communities (Al-Harthy \& Al-Badi, 2014; AlZadjali et al., 2015) It has been recognized as a fundamental human right by the United Nations. Several efforts have been made to conceptualize privacy jurists, philosophers, researchers, psychologists, and sociologists in order to give us better understanding of privacy - for example, Alan West in the research study conducted in 1960 is considered to be the first significant work highlighting the problem of consuming data privacy and data protection. West defines privacy as "the claim of individuals groups, or institutions to determine for themselves when, how, and what extent information about them is communicated to other" (Gholami and Laure, 2015).

Many studies argued that the main concern of cloud computing is the safety issue (e.g. Zissis and Lekkas, 2012; Lemoudden et al., 2013; Sandholm and Lee, 2014; Varalakshmi et al., 2014; Guo and Zheng, 2015; Al-Mascati \& Al-Badi, 2016). Specifically, challenges for enterprise applications regarding cloud computing security, which implies lack of reliable access control, standards, cipher text retrieval and processing, data exists, and reusability, data privacy, virtual security technology, and denial of services. In addition, the researchers stressed that in order to solve cloud computing's safety problems, a joint efforts of information security from technical and non-technical perspectives from academia, industrial circle, enterprise, government and related departments, are all required (Alenezi et al., 2017). Sehgal et al. (2011) argued that information security could be solved by considering three functions, which are access control, secure communications, and protection of private data. While access control contains the initial entrance by the user and the re-entry of that user or the access of additional users, the secure communication comprises any transferring of information among users (Masa'deh et al., 2016; Obeidat et al., 2016). Moreover, the protection of private data includes storage devices, processing units, and yet cache memory. Kim and Lee (2015) indicated that as security vulnerability and privacy invasion by malicious attackers or internal users could occur, various security items become essential such as confidentiality, authentication, availability, calculation efficiency, collusion resistance, forward secrecy and backward secrecy.

Lemoudden et al. (2013) stated that vulnerabilities that are relevant to the cloud usually concern the provider; among them are insufficient security audit options, lack of standard security controls regarding audit and logging certification, and continuous security monitoring. Furthermore, the researchers argued that both defense in-depth and honey pot are the foremost practical types of defense strategies in the cloud services. The first defense strategy is based on the idea that individual security controls are typically incomplete or insufficient, thus exploiting several techniques to decrease the risk when particular component security is compromised or faulty. The honey pot strategy 
aims to setup a decoy system that appears to have several vulnerabilities for easier access to its resources; and should be set up in a similar manner to those of production servers in the firm, and to be loaded with numerous fake files, directories, and other information that may look real. In turn, the decoy system will make lead the hackers believe that they have gained access to important information, whereas the honey pot collects information about the intruder and the source of the attack. This is to monitor the intruders and learn from their moves in order to figure out how they monitor and exploit the system; and finally to prevent them legitimately.

Initially, Oppenheim (2012) suggested various questions to be asked of cloud services suppliers with the purpose of a potential client can take a clear decision and avoid unpleasant surprises. These include who (both within and outside the service supplier) will be able to see my information who owns and controls your infrastructure, is this outsourced to any third party; where are the infrastructure elements located; can I see a copy of your reliability/availability/downtime reports; what service levels are guaranteed, (e.g., availability, time taken to resolve a problem)and what compensation do you offer if you fail to fulfill that; have you ever had a security breaches, and if yes you should ask for more details; do I have a contact name within your organization in case of any problems; will you abide by the local relevant data protection act; will you pay damages if a breach of the act occurs and was because of your fault; what assurances can you give to data protection standards will be maintained even if the data we supply is stored in a country with weak, or no data protection laws, or where government inspection powers are very wide ranging; how easy would it be to migrate my data to a competitor service once this contract ends; can you guarantee that it will be in a usable format; who is responsible for ID management and access control in your company; what are the names of your employees who are responsible for handling our data; what security policies, technology and systems do you use, and what national or international standards do they comply with; do I get any rights of refusal before you make changes to the services that affect my data; will you use my organization's name or type of data given to you on any of your advertising; what special measures will you take regarding data we tag as confidential; could we have a free trial with some non-sensitive data before committing ourselves; are you willing to include clauses in the contract relating to ensuring that there is no unauthorized loss or destruction of data; can you provide us with routine backups of all our data stored on your cloud; will you guarantee to inform us if you become aware of any data security breach that affects or involves our data; and most importantly, to what degree does your contact likely to be negotiable.

Sari and Kurniawan (2015) argued that there are five important and essential properties to use cloud computing in knowledge management systems including security information when it is exchanged, access to knowledge from anywhere; storage space is specified; the speed of access to knowledge; and standard of service's cost and authorized personnel access at the same time. In addition, the most important usage of cloud computing features in knowledge management appears if the team was able to access knowledge by owning an email; the easiness of knowledge management and the ability to create backup copies of the information in any loss occurs; and if establishing new branches have access to company data more easily without the need for complex systems.

\subsection{Job Opportunity and Behavioral Intention to Use Cloud Computing}

'Job opportunities' is defined as the user's perception of the degree to which the use of a new technology generates higher future employability for the users. This implies that the new skill sets acquired by the user subsequent to the use of technology improve his/her attractiveness in the job market and the potential to earn superior job. Job attributes and their influences on adoption have been included in prior studies. For example, job relevance, involvement, task technology fit and task significance, these factors refer to the importance of the technology on individuals current job accomplishment. However, individuals are often motivated to adopt new technologies on their attempts to improve their performance not only on the current job but to enhance their skills set that provide greater overall employability in the job market (Sharma et al., 2016).

\subsection{Top Management Support and Behavioral Intention to Use Cloud Computing}

Top management plays an essential role in generating innovations by providing the appropriate environment, and making decisions that enhance the creation and execution of knowledge successfully. Ideal top management shows a deep awareness of its followers needs, and provides an incentive, which is a source of encouragement and motivation for them to innovate and solve problems. Top management helps employees to address their needs for empowerment, improve personality, accomplish achievement, and enhance self-efficacy. Many researchers pointed out that top management plays an important role in organizational outcomes, and many other researchers suggested that top management support plays a key role in influencing the adoption of innovational activities in the organizations (Al Shaar, et al., 2015). 


\subsection{Competitive Pressure and Behavioral Intention to Use Cloud Computing}

Consumers and small businesses are usually concern more about the price and are less concerned about the performance guarantees. Large enterprises and government's users that are investing millions of dollars in their IT systems need to balance cost considerations against a wide range of factors including reliability, security and performance (Alenezi et al., 2015). Many enterprises and government organizations are subject to regulations surrounding the information handling and creating specific legal obligations. Integrating cloud services with existing IT infrastructure and datacentres is considered also a major issue, since new cloud services are usually extensions of existing business systems. Despite the challenges in meeting this myriad of requirements, the substantial IT budgets of large enterprises represent perhaps the largest new market for Cloud services providers (Kushida, et al., 2011).

\subsection{Regulatory Support and Behavioral Intention to Use Cloud Computing}

Unlike traditional internet services, standard contract clauses that may require additional review because of the nature of cloud computing. The parties in the contract should pay a particular attention to their rights and obligations related to notifications of breaches in security, data transfer, creation of derivative works, change of control, and access to data by law enforcement entities. Because the cloud can be used to outsource critical internal infrastructures, and the interruption of that infrastructure may have wide ranging effects, the parties should carefully take into consideration whether standard limitations on liability adequately represent allocations of liability, given the parties' the ability of using the cloud, or responsibilities for infrastructure. Since this is an issue that will crop up in every new contract that is conducted between an organization and a cloud provider, a consistent set of guidelines at a national level will be very helpful (e.g., establishing the obligation of cloud providers to notify customers of any data security breaches or formulate the liability exemptions for cloud providers for different categories of security breaches), governments therefore have to be proactive in dealing with cloud computing. Not only they will have to clarify their individual position regarding data, residency, privacy and related issues, but they will have also to recommend that an international regulatory body be formed as soon as possible with the twin role of formulating cross-border issues and consulting individual governments in formulating their own cloud-related laws. The pressing need is to mitigate issues of moral hazards - businesses or private consumers who should not be able to shop for lenient laws with respect to their data at their convenience. The formation of Euro Cloud is thus a very promising development, since it indicates that cloud computing providers are working proactively with the EU and the governments within the EU to avoid potential future roadblocks (Marston, et al., 2011).

\section{Research Methodology}

This section highlights the methodology applied in this study. It consists of the research model, operational definitions of the study's independent and dependent variables, research hypotheses besides data collection tools and research population and samples.

\subsection{Research Model}

The elements of this research were adopted from previous literature reviews, either theoretically or empirically. Indeed, this study used variables that are common in hotel management literature. Figure (1) represents a model applied in the study that shows the independent variables, the dependent variable (behavioral intention to use cloud computing), and the proposed relationship between the two variables 


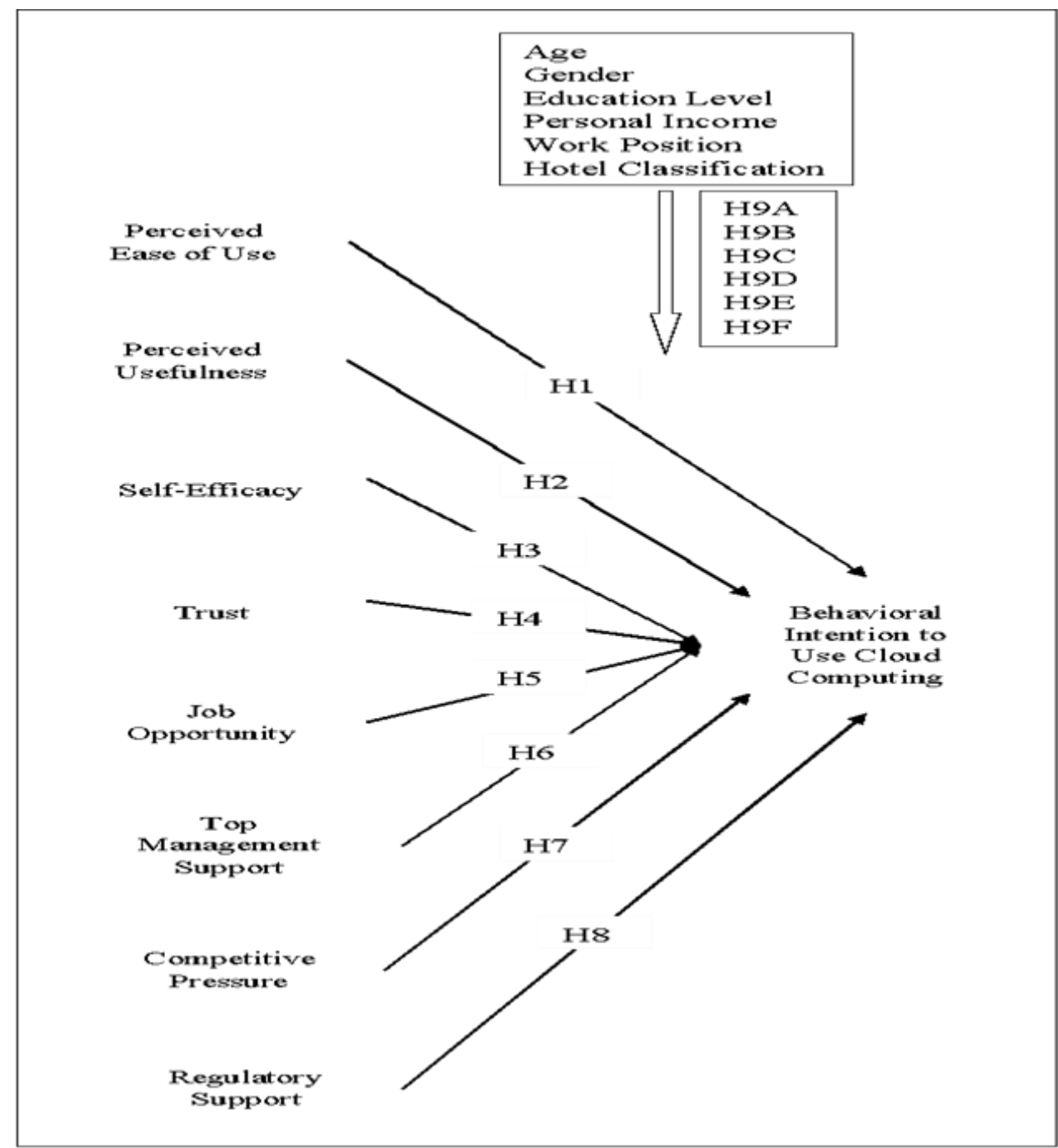

Figure 1. The proposed theoretical framework

\subsection{Operational Definitions}

Adapted from Sharma et al. (2016) and Oliveira et al. (2014), the current research considers eight independent variables that affects the employee's behavioral intention to use cloud computing services. Furthermore, the antecedents of intention to use includes perceived ease of use, perceived usefulness, self-efficacy, trust, job opportunity, top management support, competitive pressure, and regulatory support; which were measured in the research questionnaire through three, three, three, two, three, three, three, two, and three items respectively.

\subsection{Research Hypotheses}

In order to test the research model of the impacting factors in behavioral intention to use cloud computing, the study has the following hypotheses:

H1: There is a statistically significant impact of perceived ease of use on behavioral intention to use cloud computing.

$\mathrm{H} 2$ : There is a statistically significant impact of perceived usefulness on behavioral intention to use cloud computing.

H3: There is a statistically significant impact of self-efficacy on behavioral intention to use cloud computing.

H4: There is a statistically significant impact of trust on behavioral intention to use cloud computing.

H5: There is a statistically significant impact of job opportunity on behavioral intention to use cloud computing.

H6: There is a statistically significant impact of top management support on behavioral intention to use cloud 
computing.

H7: There is a statistically significant impact of competitive pressure on behavioral intention to use cloud computing.

H8: There is a statistically significant impact of regulatory support on behavioral intention to use cloud computing.

H9A: There is a significant difference in the impact of behavioral intention to use cloud computing due to gender.

H9B: There is a significant difference in the impact of behavioral intention to use cloud computing due to age.

H9C: There is a significant difference in the impact of behavioral intention to use cloud computing due to educational level.

H9D: There is a significant difference in the impact of behavioral intention to use cloud computing due to personal income.

H9E: There is a significant difference in the impact of behavioral intention to use cloud computing due to work position.

H9F: There is a significant difference in the impact behavioral intention to use cloud computing due to the hotel classification.

\subsection{Population and Sampling}

The targeted population of this study consisted of all staff who know cloud computing services and working in Aqaba city hotels located in Jordan, specifically hotels three, four and five stars. Thus, a judgment sampling technique was conducted. A total of 205 questionnaires was returned and applicable for statistical analysis. Indeed, the primary data was collected through a drop-and-collect survey technique. The surveys were distributed to the target staff working in the hotels that agreed to participate in the study. The questionnaire consists of two sections; the first section presents general personal information about the respondent, the gender, the age, the educational level, the personal income, the work position and the hotel classification of the hotel. The second section includes questions to measure the independent and dependent variables based on their operational definitions.

\section{Data Analysis and Results}

In order to explore the impacts of perceived ease of use, perceived usefulness, self-efficacy, trust, job opportunity, top management support, competitive pressure, and regulatory support on behavioral intention to use cloud computing, in which these variables have been measured using 5-points Likert scale that varies between strongly disagree $=1$ and strongly agree $=5$. Moreover, reliability and validity analyses were conducted; descriptive analysis also was used to describe the characteristics of the sample and the respondent to the questionnaires besides the independent and dependent variables. Also, multiple regression analysis was employed to test the proposed hypotheses.

\subsection{Validity and Reliability}

Validity and reliability are two important measures to determine the quality and usefulness of the primary data. Validity is about accuracy and whether the instrument measures what it is intended to measure, while reliability is about precision; it is used to check the consistency and stability of the questionnaire. Indeed, the researchers adopted scales and items that were previously developed and used by other researchers with similar interest. A draft of the questionnaire was formulated, and then it was reviewed by four academic lecturers -who have a sufficient knowledge and experience in this field- to ensure that each item is measuring what is intended to be measured, and to avoid the ambiguity and complexity in the structure of the questions. The reliability of the instrument was measured by the Cronbach's alpha coefficient. Furthermore, some scholars (e.g. Bagozzi and Yi, 1988) suggested that the values of all indicators or dimensional scales should be above the recommended value of 0.60 . Table 1 represents the results of Cranach's alpha for the independent and dependent variables. Cronbach's alpha coefficients of all the tested variables are above 0.60 which suggest that the composite measure is reliable. 
Table 1. The Cronbach's alpha coefficients of study variables

\begin{tabular}{lcc}
\hline Variables & Number of items & Cronbach alpha \\
\hline Perceived ease of use & 3 & 0.781 \\
Perceived usefulness & 3 & 0.783 \\
Self-efficacy & 3 & 0.671 \\
Trust & 2 & 0.738 \\
Job opportunity & 3 & 0.744 \\
Top management support & 3 & 0.680 \\
Competitive pressure & 3 & 0.697 \\
Regulatory support & 2 & 0.637 \\
Behavioral intention to use cloud computing & 3 & 0.878 \\
\hline
\end{tabular}

\subsection{Respondents Demographic Profile}

As indicated in Table 2, the demographic profile of the respondents for this study shows that they are typically females, executive managers and supervisors; most of them between 25 to 40 years old who working in three and four star hotels; the majorities hold bachelor degrees; and most of them earn 750 to1500 \$ monthly.

Table 2. Description of the respondents' demographic profiles

\begin{tabular}{|c|c|c|c|}
\hline Category & Category & Frequency & Percentage $\%$ \\
\hline \multirow[t]{3}{*}{ Gender } & Males & 70 & 34.1 \\
\hline & Females & 135 & 65.9 \\
\hline & Total & 205 & 100 \\
\hline \multirow[t]{5}{*}{ Age } & 18 years - less than 25 & 34 & 16.6 \\
\hline & 25 years - less than 30 & 64 & 31.2 \\
\hline & 30 years - less than 40 & 88 & 42.9 \\
\hline & More than 40 years old & 19 & 9.3 \\
\hline & Total & 205 & 100 \\
\hline \multirow[t]{7}{*}{ Education level } & Less than high school & 17 & 8.3 \\
\hline & High school & 34 & 16.6 \\
\hline & Diploma & 58 & 28.3 \\
\hline & Bachelor & 71 & 34.6 \\
\hline & Master & 21 & 10.2 \\
\hline & Doctorate & 4 & 2.0 \\
\hline & Total & 205 & 100 \\
\hline \multirow{4}{*}{$\begin{array}{l}\text { Personal income }(\$) \\
\text { monthly }\end{array}$} & Less than 750 & 79 & 38.5 \\
\hline & 750 - less than 1500 & 98 & 47.8 \\
\hline & More than 1500 & 28 & 13.7 \\
\hline & Total & 205 & 100 \\
\hline \multirow[t]{5}{*}{ Work position } & Head of department & 33 & 16.1 \\
\hline & Director & 32 & 15.6 \\
\hline & Executive manager & 81 & 39.5 \\
\hline & Supervisor & 59 & 28.8 \\
\hline & Total & 205 & 100 \\
\hline \multirow[t]{4}{*}{ Hotel classification } & Three star & 97 & 47.3 \\
\hline & Four star & 88 & 42.9 \\
\hline & Five star & 20 & 9.8 \\
\hline & Total & 205 & 100 \\
\hline
\end{tabular}




\subsection{Descriptive Analysis}

In order to describe the responses and thus the attitude of the respondents toward each question they were asked in the questionnaire, the mean and the standard deviation were estimated. While the mean shows the central tendency of the data, the standard deviation measures the dispersion which offers an index of the spread or variability in the data (Sekaran and Bougie, 2013). In other words, a small standard deviation for a set of values reveals that these values are clustered closely about the mean or located close to it; while a large standard deviation indicates the opposite. The level of each item was determined by the following formula: (highest point in Likert scale - lowest point in Likert scale) / the number of the levels used $=(5-1) / 5=0.80$, where 1-1.80 reflected by "very low", 1.81-2.60 reflected by "low", 2.61-3.40 reflected by "moderate", 3.41-4.20 reflected by "high", and 4.21-5 reflected by "very high". Then the items were ordered based on their means. Tables 3 and 4 show the results.

Table 3. Overall mean and standard deviation of the study's variables

\begin{tabular}{llcc}
\hline Type of Variable & Variables & Mean & Standard Deviation \\
\hline Independent Variables & Perceived ease of use & 3.07 & 0.82 \\
& Perceived usefulness & 3.24 & 0.76 \\
& Self-efficacy & 3.23 & 0.79 \\
& Trust & 3.08 & 0.86 \\
& Job opportunity & 3.19 & 0.76 \\
& Top management support & 2.99 & 0.78 \\
& Competitive pressure & 3.06 & 0.73 \\
Dependent Variable & Regulatory support & 3.05 & 0.70 \\
& Behavioral intention to use cloud computing & 3.32 & 0.90
\end{tabular}

As presented in Table 3, data analysis results have shown that perceived ease of use, perceived usefulness, self-efficacy, trust, job opportunity, top management support, competitive pressure, regulatory support, and behavioral intention to use cloud computing in Aqaba three, four, and five star hotels are applied in moderate levels in which the mean scores 2.99-3.32. Table 4 demonstrates the mean, standard deviations, level, and order scores for each variable items.

Table 4. Mean and standard deviation of the study's variables

\begin{tabular}{lcc}
\hline Perceived ease of use & Mean & SD \\
\hline I think learning how to use Cloud Computing services is easy & 2.90 & 1.14 \\
I think learning how to use Cloud Computing services requires less mental efforts & 3.08 & 0.94 \\
I think Cloud Computing services is easy & 3.21 & 0.85 \\
Perceived usefulness & Mean & SD \\
I think adopting Cloud Computing services will improve my performance & 3.22 & 0.93 \\
I think adopting Cloud Computing services will improve my productivity & 3.25 & 0.89 \\
I think adopting Cloud Computing services will be useful for my overall work & 3.24 & 0.90 \\
Self-efficacy & Mean & SD \\
I will be confident in using Cloud Computing services & 3.19 & 1.00 \\
I will have experience in using Cloud Computing services so fast & 3.28 & 1.05 \\
I encourage hotels to adopt Cloud Computing services & 3.22 & 0.99 \\
Trust & Mean & SD \\
I am confident about the security available with Cloud Computing technology & 3.02 & 0.94 \\
I am confident about the privacy and integrity of data made available through Cloud & 3.13 & 1.00
\end{tabular}

Computing 
Job opportunity

I think adopting Cloud Computing will create new job opportunities

Learning Cloud Computing will provide more job options to me in the future

Hotels adopting Cloud Computing will require more experts in the future

Top management support

The hotel's management will support the implementation of cloud computing

The hotel's top management will provide strong leadership and engage in the process when it comes to information systems

The hotel's management is willing to take risks (financial and organizational) involved in the adoption of cloud computing

Competitive pressure

My hotel thinks that cloud computing will have an influence on competition in their industry

Our hotel is under pressure from competitors to adopt cloud computing

Some of our competitors have already started using cloud computing

Regulatory support

I think there is legal protection in the use of cloud computing

I think the laws \& regulations that exist nowadays are sufficient to protect the use of cloud computing

Behavioral intention to use cloud computing

I intend to use cloud computing in the future

I predict I would use cloud computing in the future

I plan to use cloud computing in the future

\begin{tabular}{cc} 
Mean & SD \\
3.20 & 0.98 \\
3.24 & 0.88 \\
3.13 & 0.96 \\
Mean & SD \\
3.14 & 0.96 \\
3.10 & 1.01 \\
& \\
2.76 & 1.02 \\
& \\
Mean & SD \\
3.07 & 0.95 \\
3.04 & 0.91 \\
3.06 & 0.91 \\
Mean & SD \\
3.01 & 0.82 \\
3.10 & 0.80 \\
& \\
Mean & SD \\
3.19 & 1.00 \\
3.37 & 0.98 \\
3.40 & 1.04 \\
\hline
\end{tabular}

\subsection{Hypotheses Testing Results}

The current research aims to investigate the impact of perceived ease of use, perceived usefulness, self-efficacy, trust, job opportunity, top management support, competitive pressure, and regulatory support on behavioral intention to use cloud computing services. Consequently, in order to test the hypotheses developed for this study, multiple regression technique was used. Furthermore, the level of significance ( $\alpha$-level) was chosen to be 0.05 and the probability value (p-value) obtained from the statistical hypotheses test is considered to be the decision rule for rejecting the null hypotheses (Creswell, 2009). Thus, if the p-value is less than or equal to $\alpha$-level, the null hypothesis will be rejected and the alternative hypothesis will be supported. However, if the p-value is greater than the $\alpha$-level, the null hypothesis cannot be rejected and the alternative hypothesis will not be supported. In addition, the normality of the independent variables and the absence of multicolinearity problem (a case of multiple regression in which the independent variables are themselves highly correlated) were checked. According to Pallant (2005), most values should be inside the adequate ranges for normality (i.e. -1.0 to +1.0 ). The results of skewness and Variance Inflation Factor (VIF) can be shown in Table 5.

Table 5. Skewness and VIF for the independent variables

\begin{tabular}{lccc}
\hline Variables & Tolerance & VIF & Skewness \\
\hline Perceived ease of use & 0.750 & 1.333 & 0.75 \\
Perceived usefulness & 0.613 & 1.630 & 0.61 \\
Self-efficacy & 0.486 & 2.057 & 0.48 \\
Trust & 0.520 & 1.925 & 0.51 \\
Job opportunity & 0.581 & 1.722 & 0.58 \\
Top management support & 0.552 & 1.810 & 0.55 \\
Competitive pressure & 0.694 & 1.440 & 0.69 \\
Regulatory support & 0.758 & 1.319 & 0.75 \\
\hline
\end{tabular}


As can be noticed from Table 5, the skewness values were within the normal values $(-1.0$ to +1.0$)$ suggesting that the data of the independent variables is normal. The VIF values were less than the critical value (10) which is most common among most studies, suggesting no multicolinearity problem among the independent variables. However, the results of testing the eight hypotheses can be shown in Table 6 .

Table 6. Result for the study model (b)

\begin{tabular}{llllllllc}
\hline Variable & $\mathrm{r}$ & $\mathrm{R} 2$ & $\mathrm{f}$ & $\mathrm{Sig}(\mathrm{f})$ & $\beta$ & $\mathrm{t}$ & $\mathrm{Sig}(\mathrm{t})$ & $\begin{array}{c}\text { Empirical } \\
\text { Evidence }\end{array}$ \\
\hline Perceived ease of use & 0.661 & 0.437 & 19.004 & $0.000 \mathrm{a}$ & 0.114 & 1.681 & 0.094 & Not supported \\
Perceived usefulness & & & & & 0.075 & 0.915 & 0.361 & Not supported \\
Self-efficacy & & & & & 0.100 & 1.133 & 0.259 & Not supported \\
Trust & & & & & 0.068 & 0.871 & 0.385 & Not supported \\
Job opportunity & & & & & 0.319 & 3.840 & 0.000 & Supported \\
Top management support & & & & & 0.166 & 1.983 & 0.049 & Supported \\
Competitive pressure & & & & & 0.257 & 3.217 & 0.002 & Supported \\
Regulatory support & & & & & 0.255 & 3.198 & 0.002 & Supported \\
\hline
\end{tabular}

a. Predictors: (Constant), perceived ease of use, perceived usefulness, self-efficacy, trust, job opportunity, top management support, competitive pressure, and regulatory support

b. Dependent variable: Behavioral intention to use cloud computing

Refer to Table 6 the multiple correlation coefficient $\mathrm{R}=0.661$ indicates that there is a strong positive correlation between the independent variables (perceived ease of use, perceived usefulness, self-efficacy, trust, job opportunity, top management support, competitive pressure, and regulatory support) and behavioral intention to use cloud computing. The R2 indicates the generalizability of the model. It allows us to generalize the results taken from the respondents to the whole population. In this case, it equals 0.437 . The results showed that F-ratio for these data is equal to 19.004 , which is statistically significant at $\mathrm{p}<0.05$. Therefore, we conclude that there is a statistically significant impact of the independent variables on behavioral intention to use cloud computing.

The $\beta$ indicates the individual contribution in each predictor (independent variable) to the model, if other predictors are held constant. Table 6 shows the standardized coefficients for each independent variable. The value of $\beta$ for perceived ease of use, perceived usefulness, self-efficacy, and trust are $0.114,0.075,0.100$, and 0.068 , which considered to be small values compared with other predictors, and not significant at $\mathrm{p} \leq 0.05$. Thus, $\mathrm{H} 1-\mathrm{H} 4$ were not supported. While the value of $\beta$ for job opportunity, top management support, competitive pressure, and regulatory support are $0.319,0.166,0.257$, and 0.255 respectively, which are positive, significant at $p \leq 0.05$. The level of the effect of these variables depends on the $\beta$ value, the higher $\beta$ value is, the higher effect will it makes in dependent variable. We can infer from the values of beta that the variable, which has the highest contribution in the model, is job opportunity, followed by competitive pressure, regulatory support, and finally top management support.

Hypotheses H9A, H9B, H9C, H9D, H9E, and H9F indicated that there is a significant difference in the impact of behavioral intention to use cloud computing due to gender, age, educational level, personal income, work position, and hotel classification. Independent Samples T-test was employed in order to investigate if there is any significant differences in the impact of behavioral intention to use cloud computing that can be attributed to gender. In addition, ANOVA test was employed to examine if there is any significant differences in the impact of behavioral intention to use cloud computing which can be attributed to age, educational level, personal income, work position, and hotel classification. Results of T-test, shown in Table 7, indicated that there is a significant difference in the impact of behavioral intention to use cloud computing that can be attributed to gender. However, results of ANOVA's test, depicted in Table 8, Table 9, and Table 10 indicates that there is no significant difference in the impact of behavioral intention to use cloud computing in favor of age, educational level, and personal income; whereas a significant difference found in favor of work position and hotel classification, see Table 11 and Table 12. 
Table 7. T-test of behavioral intention to use cloud computing due to gender

\begin{tabular}{|c|c|c|c|c|c|c|c|c|c|}
\hline \multirow[t]{2}{*}{ Variables } & \multicolumn{2}{|c|}{ Male } & \multicolumn{4}{|c|}{ Female } & \multirow[t]{2}{*}{$\mathrm{T}$} & \multirow[t]{2}{*}{ df. } & \multirow[t]{2}{*}{ Sig. } \\
\hline & $\mathrm{N}$ & Mean & Std & $\mathrm{N}$ & Mean & Std & & & \\
\hline $\begin{array}{l}\text { Support for } \\
\text { sustainable } \\
\text { tourism } \\
\text { development }\end{array}$ & 70 & 3.1333 & 0.87624 & 135 & 3.4198 & 0.91056 & 2.190 & 144.566 & 0.030 \\
\hline
\end{tabular}

Table 8. ANOVA Analysis of behavioral intention to use cloud computing due to age

\begin{tabular}{lllllll}
\hline Variables & & Sum of Squares & Df & Mean Square & F & Sig. \\
\hline $\begin{array}{l}\text { Support for } \\
\text { sustainable } \\
\text { tourism } \\
\text { development }\end{array}$ & Between & 1.726 & 3 & 0.575 & 0.696 & 0.556 \\
\cline { 2 - 7 } & Groups & Within & 166.137 & 201 & 0.827 & \\
\hline
\end{tabular}

Table 9. ANOVA Analysis of behavioral intention to use cloud computing due to educational level

\begin{tabular}{|c|c|c|c|c|c|c|}
\hline \multirow{2}{*}{\multicolumn{2}{|c|}{\begin{tabular}{ll}
\multicolumn{2}{l}{ Variables } \\
Support for & Between \\
sustainable & Groups
\end{tabular}}} & Sum of Squares & Df & Mean Square & $\mathrm{F}$ & Sig. \\
\hline \multirow{3}{*}{$\begin{array}{l}\text { Support for } \\
\text { sustainable } \\
\text { tourism } \\
\text { development }\end{array}$} & & 5.112 & 5 & 1.022 & 1.250 & 0.287 \\
\hline & $\begin{array}{l}\text { Within } \\
\text { Groups }\end{array}$ & 162.751 & 199 & 0.818 & & \\
\hline & Total & 167.862 & 204 & & & \\
\hline
\end{tabular}

Table 10. ANOVA Analysis of behavioral intention to use cloud computing due to personal income

\begin{tabular}{lllllll}
\hline Variables & & Sum of Squares & Df & Mean Square & F & Sig. \\
\hline \begin{tabular}{l} 
Support for $\begin{array}{l}\text { sustainable } \\
\text { tourism } \\
\text { development }\end{array}$ \\
\cline { 2 - 6 }
\end{tabular} & $\begin{array}{l}\text { Between } \\
\text { Groups }\end{array}$ & 2.021 & 2 & 1.011 & 1.231 & 0.294 \\
\cline { 2 - 7 } & Groups & 165.841 & 202 & 0.821 & & \\
\cline { 2 - 6 } & Total & 167.862 & 204 & & \\
\hline
\end{tabular}

Table 11. ANOVA Analysis of behavioral intention to use cloud computing due to work position

\begin{tabular}{lllllll}
\hline Variables & & Sum of Squares & Df & Mean Square & F & Sig. \\
\hline \begin{tabular}{l} 
Support for $\begin{array}{l}\text { sustainable } \\
\text { tourism } \\
\text { development }\end{array}$ \\
\cline { 2 - 6 }
\end{tabular} & Between & 9.410 & 3 & 3.137 & 3.979 & 0.009 \\
\cline { 2 - 6 } & Within & 158.452 & 201 & 0.788 & & \\
\cline { 2 - 7 } & Troups & 167.862 & 204 & & & \\
\hline
\end{tabular}

Table 12. ANOVA Analysis of behavioral intention to use cloud computing due to hotel classification

\begin{tabular}{lllllll}
\hline Variables & & Sum of Squares & Df & Mean Square & F & Sig. \\
\hline \begin{tabular}{l} 
Support for $\begin{array}{l}\text { sustainable } \\
\text { tourism } \\
\text { development }\end{array}$ \\
\cline { 2 - 6 }
\end{tabular} & Between & 10.158 & 2 & 5.079 & 6.506 & 0.002 \\
\cline { 2 - 4 } & Wroups & 157.704 & 202 & 0.781 & & \\
\cline { 2 - 7 } & Groups & 167.862 & 204 & & \\
\hline
\end{tabular}




\section{Discussion, Recommendations and Future Studies}

The primary goal of this research was to propose and test an augmented model that examine the factors that may influence the adoption of cloud computing service in hotels. Our results show that job opportunity, competitive pressure was the strong and the most effective reason to accept and apply cloud computing in the framework. Top management support and regulatory support came as a supporting factor to adopt cloud computing services. what makes this study more interesting is that most of the companies did not mention that ease of use, usefulness, self-efficacy and trust $\mathrm{h}$ will affect their acceptance of using new technology. In addition, the most important thing is trust of using the new technology, if companies would like to adopt new technologies then they should determine if this new technology will make impact in creating more job opportunities and will lead to more competitive advantages among other companies. Hence, based on the above discussion, the current study recommends:

A: Making cloud computing more suitable for companies to use for purchasing or leasing softwares that helps companies to achieve their needs.

B: Making cloud computing more reliable and secured for companies and institutions.

C: Governments should have a key role in supporting regulations and regulatory statements regarding cloud computing, and provide he needs to apply cloud computing.

The current study has some limitations. The current study has been primarily conducted in Aqaba and may not be a representative of the entire Jordan, our data collection was conducted at the very initial stage of cloud computing; many firms are actually still at the imagination stage rather than the usage stage of cloud in small and big businesses. In this study, we proposed a model that is able to examine the factors that may hinder or enable the adoption of cloud computing services. Cross-cultural studies across countries could be undertaken to further validate the model across different cultures. Furthermore, future research could use mixed method to uncover more dimensions and have a deep understanding why the employees react to adopting and using the technology in different ways.

\section{References}

Abbasi, M. S., Elyas, T., \& Shah, F. (2015). Impact of individualism and collectivism over the individual's technology acceptance behaviour: A multi-group analysis between Pakistan and Turkey. Journal of Enterprise Information Management, 28(6), 747-768. https://doi.org/10.1108/JEIM-12-2014-0124

Alalwan, A., Rana, N., Algharabat, R., \& Tarhini, A. (2016). A Systematic Review of Extant Literature in Social Media in the Marketing Perspective. The 15th IFIP Conference on e-Business, e-Services and e-Society, Swansea, UK (13-15, Sep 2016) (pp.79-89). Springer International Publishing.

Al-Badi, A., Tarhini, A., \& Al-Kaaf, W. (2017). Financial Incentives for Adopting Cloud Computing in Higher Educational Institutions. Asian Social Science, 13(4), 162-174. https://doi.org/10.5539/ass.v13n4p162

Al-Badi, A., Tarhini, A., \& Al-Sawaei, S. (2017). Utilizing Social Media to Encourage Domestic Tourism in Oman. International Journal of Business and Management, 12(4), 84-94. https://doi.org/10.5539/ijbm.v12n4p84

Al-Dmour, H., Al-Madani, S., Alansari, I., \& Al-Dmour, R. (2016). Factors Affecting the Effectiveness of Cause-Related Marketing Campaign: Moderating Effect of Sponsor-Cause Congruence. International Journal of Marketing Studies, 8(5), 114-127. https://doi.org/10.5539/ijms.v8n5p114

Alenezi, H., Tarhini, A., \& Sharma, S. K. (2015). Development of a Quantitative Model to Investigate the Strategic Relationship between Information Quality and e-Government Benefits. Transforming Government: People, Process and Policy, 9(3), 324-351. https://doi.org/10.1108/TG-01-2015-0004

Alenezi, H., Alalwan, A., \& Al-Qirim, N. (2017). Factors Affecting e-Government Adoption in Kuwait: A Qualitative study. Electronic Journal of e-Government, 15(2), 84-102.

Al-Harthy, L. Y., \& Al-Badi, A. H. (2014). To Cloudify or Not to Cloudify. World Academy of Science, Engineering and Technology, International Journal of Social, Behavioral, Educational, Economic, Business and Industrial Engineering, 8(8), 2453-2464.

Alijani, G. S., Fulk, H. K., Omar, A., \& Tulsi, R. (2014). Cloud Computing Effects on Small Business. The Entrepreneurial Executive, 19(35), 1-12.

AlKharusi, M. H., \& Al-Badi, A. H. (2016, March). IT personnel perspective of the slow adoption of cloud computing in public sector: Case study in Oman. In 3rd MEC International Conference on Big Data and Smart City (ICBDSC), 2016 (pp. 1-8). IEEE. https://doi.org/10.1109/ICBDSC.2016.7460364 
Al-lawati, A., \& Al-Badi, A. H. (2016, March). The impact of cloud computing IT departments: A case study of Oman's financial institutions. In 3rd MEC International Conference on Big Data and Smart City (ICBDSC), Muscat, Oman, 2016 (pp. 1-10). IEEE. https://doi.org/10.1109/ICBDSC.2016.7460344

Al-Mascati, H., \& Al-Badi, A. H. (2016, March). Critical success factors affecting the adoption of cloud computing in oil and gas industry in Oman. In 3rd MEC International Conference on Big Data and Smart City (ICBDSC), Muscat, Oman, 2016 (pp. 1-7). IEEE. https://doi.org/10.1109/ICBDSC.2016.7460365

Al-Musawi, F., Al-Badi, A. H., \& Ali, S. (2015, September). A Road Map to Risk Management Framework for Successful Implementation of Cloud Computing in Oman. In International Conference on Intelligent Networking and Collaborative Systems (INCOS), 2015, Taipei, Taiwan (pp. 417-422). IEEE. https://doi.org/10.1109/incos.2015.80

Al-Qirim, N. (2011, April). A Roadmap for success in the clouds. In International Conference on Innovations in Information Technology (IIT), 2011, Fukuoka, Japan (pp. 271-275). IEEE. https://doi.org/10.1109/innovations.2011.5893831

Al-Qirim, N., Rouibah, K., Serhani, M. A., Yammahi, A. R., \& Yammahi, M. A. (2017). Learning Orientations of IT Higher Education Students in UAE University. Education and Information Technologies. 1-14. https://doi.org/10.1007/s10639-017-9589-y

Al-Shaar, E. M., Khattab, S. A., Alkaied, R. N., \& Manna, A. Q. (2015). The Effect of Top Management Support on Innovation: The Mediating Role of Synergy between Organizational Structure and Information Technology. International Review of Management and Business Research, 4(2), 499-513.

Altamony, H., Alshurideh, M., \& Obeidat, B. (2012, May). Information systems for competitive advantage: Implementation of an organisational strategic management process. In Proceedings of the 18th IBIMA conference on innovation and sustainable economic competitive advantage, Istanbul, Turkey, 9th-10th May.

AlZadjali, A. M., Al-Badi, A. H., \& Ali, S. (2015, September). An Analysis of the Security Threats and Vulnerabilities of Cloud Computing in Oman. In Intelligent Networking and Collaborative Systems (INCOS), 2015 International Conference on (pp. 423-428). IEEE. https://doi.org/10.1109/incos.2015.79

Bagozzi, R., \& Yi, Y. (1988). On the Evaluation of Structural Evaluation Models. Journal of the Academy of Marketing Science, 16(1), 74-94. https://doi.org/10.1007/BF02723327

Creswell, J. (2009). Research Design: Qualitative, Quantitative, and Mixed Methods Approaches (3rd ed.). Thousand Oaks: Sage Publications.

Daylami, N. (2015). The Origen and Construct of Cloud Computing. International Journal of the Academic Business World, 9(2), 1-5.

Dwivedi, Y. K., \& Mustafee, N. (2010). It's unwritten in the Cloud: the technology enablers for realising the promise of Cloud Computing. Journal of Enterprise Information Management, 23(6), 673-679. https://doi.org/10.1108/17410391011088583

El-Masri, M., \& Tarhini, A. (2017). Factors affecting the adoption of e-learning systems in Qatar and USA: Extending the Unified Theory of Acceptance and Use of Technology 2 (UTAUT2). Educational Technology Research and Development, 65(3), 743-763. https://doi.org/10.1007/s11423-016-9508-8

El-Masri, M., Orozco, J., Tarhini, A., \& Tarhini, T. (2015). The Impact of IS-Business Alignment Practices on Organizational Choice of IS-Business Alignment Strategies. The 19th Pacific Asia Conference on Information Systems (PACIS 2015), Paper 215, Singapore, 6-9 July 2015.

Gholami, A., \& Laure, E. (2015). Security and Privacy of Sensitive Data in Cloud Computing: A Survey of Recent Developments. Computer Science \& Information Technology (CS \& IT), 131-150. https://doi.org/10.5121/csit.2015.51611

Guo, C., \& Zheng, X. (2015). The Research of Data Security Mechanism based on Cloud Computing. International Journal of Security and Its Applications, 9(3) 363-370. https://doi.org/10.14257/ijsia.2015.9.3.28

Gupta, P., Seetharaman, A., \& Raj, J. R. (2013). The Usage and Adoption of Cloud Computing by Small and Medium Businesses. International Journal of Information Management, 33(5), 861-874. https://doi.org/10.1016/j.ijinfomgt.2013.07.001

Hsu, P. F., Ray, S., \& Li-Hsieh, Y. Y. (2014). Examining Cloud Computing Adoption Intention, Pricing Mechanism, 
and Deployment Model. International Journal of Information Management, 34(4), 474-488. https://doi.org/10.1016/j.ijinfomgt.2014.04.006

Karajeh, H., \& Maqableh, M. (2016). Privacy and Security Issues of Cloud Computing Environment. In Proceedings of the 23rd IBIMA Conference Vision 2020 (pp. 1-15).

Kateb, G. A., Swies, R., \& Maqableh, M. (2014). An Investigation on the Critical Factors of Information System Implementation in Jordanian Information Technology Companies. European Journal of Business and Management, 7(36), 11-28.

Kim, S., \& Lee, I. (2015). Study on User Authority Management for Safe Data Protection in Cloud Computing Environments. Symmetry, 7, 269-283. https://doi.org/10.3390/sym7010269

Kushida, K. E., Murray, J., \& Zysman, J. (2011). Diffusing the Cloud: Cloud Computing and Implications for Public Policy. Journal of Industry, Competition and Trade, 11(3), 209-237. https://doi.org/10.1007/s10842-011-0106-5

Lemoudden, M., Bouazza, N., Ouahidi, B., \& Bourget, D. (2013). A Survey of Cloud Computing Security Overview of Attack Vectors and Defense Mechanisms. Journal of Theoretical and Applied Information Technology, 54(2), 325-330.

Maqableh, M., \& Karajeh, H., (2014). Job Scheduling for Cloud Computing Using Neural Networks. Communications and Network, 6(3), 191-200. https://doi.org/10.4236/cn.2014.63021

Marston, S., Li, Z., Bandyopadhyay, S., Zhang, J., \& Ghalsasi, A. (2011). Cloud Computing-The Business Perspective. Decision Support Systems, 51(1), 176-189. https://doi.org/10.1016/j.dss.2010.12.006

Mas'adeh, R. (2016). Cloud Computing Perceived Importance in the Middle Eastern Firms: The Cases of Jordan, Saudi Arabia and United Arab Emirates from the Operational Level. Communications and Network, 8(3), 103-118. https://doi.org/10.4236/cn.2016.83011

Masa'deh, R., Obeidat, B. Y., \& Tarhini, A. (2016). A Jordanian Empirical Study of the Associations Among Transformational Leadership, Transactional Leadership, Knowledge Sharing, Job Performance, and Firm Performance: A Structural Equation Modelling Approach. Journal of Management Development, 35(5), 681-705. https://doi.org/10.1108/JMD-09-2015-0134

Masa'deh, R., Shannak, R., Maqableh, M., \& Tarhini, A. (2017). The Impact of Knowledge Management on Job Performance in Higher Education: The Case of the University of Jordan. Journal of Enterprise Information Management, 30(2), 244-262. https://doi.org/10.1108/JEIM-09-2015-0087

Mohammed, A. B., \& Maqableh, M. (2016). Modeling Factors Affecting Student's Usage Behaviour of E-Learning Systems in Lebanon. International Journal of Business and Management, 11(2), 299-312. https://doi.org/10.5539/ijbm.v11n2p299

Obeidat, B. Y., Al-Suradi, M., \& Tarhini, A. (2016). The Impact of Knowledge Management on Innovation: An Empirical Study on Jordanian Consultancy Firms. Management Research Review, 39(10), 1214-1238. https://doi.org/10.1108/MRR-09-2015-0214

Obeidat, B. Y., Shannak, R. O., \& Al-Jarrah, I. (2012). Toward better understanding for Arabian culture: Implications based on Hofstede's cultural model. European Journal of Social Sciences, 28(4), 512-522. https://doi.org/10.1016/j.im.2014.03.006

Oliveira, T., Thomas, M., \& Espadanal, M. (2014). Assessing the Determinants of Cloud Computing Adoption: An Analysis of the Manufacturing and Services Sectors. Information \& Management, 51, 497-510.

Oppenheim, C. (2012). Cloud Law and Contracts Negotiation. El Profesional de la Información, 21(5), 453-457. https://doi.org/10.3145/epi.2012.sep.02

Orozco, J., Tarhini, A., \& Tarhini, T. (2015). A framework of IS/business alignment management practices to improve the design of IT Governance architectures. International Journal of Business and Management, 10(4), 1-12. https://doi.org/10.5539/ijbm.v10n4p1

Pallant, J. (2005). SPSS Survival Manual: A Step Guide to Data Analysis Using SPSS for Windows Version 12. Chicago, Illinois: Open University Press.

Sandholm, T., \& Lee, D. (2014). Notes on Cloud Computing Principles. Journal of Cloud Computing: Advances, Systems and Applications, 3(21), 1-10. https://doi.org/10.1186/s13677-014-0021-5

Sari, R., \& Kurniawan, Y. (2015). Cloud Computing Technology Infrastructure to Support the Knowledge 
Management Process (A Case Study Approach). Journal of Theoretical and Applied Information Technology, 73(3), 377-382.

Sehgal, N., Sohoni, S., Xiong, Y., Fritz, D., Mulia, W., \& Acken, J. (2011). Cross Section of the Issues and Research Activities Related to both Information Security and Cloud Computing. IETE Technical Review, 28(4), 279-291. https://doi.org/10.4103/0256-4602.83549

Sekaran, U., \& Bougie, R. (2013). Research Methods for Business: A Skill-Building Approach (6th ed.). New York: Wiley.

Sharma, S. K., Al-Badi, A. H., Govindaluri, S. M., \& Al-Kharusi, M. H. (2016). Predicting Motivators of Cloud Computing Adoption: A Developing Country Perspective. Computers in Human Behavior, 62, 61-69. https://doi.org/10.1016/j.chb.2016.03.073

Sharma, S. K., Govindaluri, M. S., Al-Muharrmi, S., \& Tarhini, A. (2017). A multi-analytical model for mobile banking adoption: A developing country perspective. Review of International Business and Strategy, 27(1), 222-237. https://doi.org/10.1108/RIBS-11-2016-0074

Tarhini, A., Arachchilage, N. A. G., \& Abbasi, M.S. (2015a). A Critical Review of Theories and Models of Technology Adoption and Acceptance in Information System Research. International Journal of Technology Diffusion (IJTD), 6(4), 58-77. https://doi.org/10.4018/IJTD.2015100104

Tarhini, A., Hone, K., \& Liu, X. (2015b). A cross-cultural examination of the impact of social, organisational and individual factors on educational technology acceptance between British and Lebanese university students. British Journal of Educational Technology, 46(4), 739-755. https://doi.org/10.1111/bjet.12169

Tarhini, A., El-Masri, M., Ali, M., \& Serrano, A. (2016). Extending the UTAUT model to understand the customers' acceptance and use of internet banking in Lebanon: A structural equation modeling approach. Information Technology and People, 29(4), 830-849. https://doi.org/10.1108/ITP-02-2014-0034

Varalakshmi, A., Haleema, P., Subalakshmi, R., \& Iyengar, N. (2014). Quality based Solution for Adaptable and Scalable Access Control in Cloud Computing. International Journal of Grid Distribution Computing, 7(6), 137-148. https://doi.org/10.14257/ijgdc.2014.7.6.11

Yadav, R., Sharma, S.K., \& Tarhini, A. (2016). A multi-analytical approach to understand and predict the mobile commerce adoption. Journal of Enterprise and Information Management, 29(2), 222-237. https://doi.org/10.1108/JEIM-04-2015-0034

Zissis, D., \& Lekkas, D. (2012). Addressing Cloud Computing Security Issues. Future Generation Computer Systems, 28, 583-592. https://doi.org/10.1016/j.future.2010.12.006 